\title{
SPAD array chips with full frame readout for crystal characterization
}

\author{
Peter Fischer ${ }^{1 *}$, Roberto Blanco ${ }^{1}$, Ilaria Sacco ${ }^{1}$, Michael Ritzert ${ }^{1}$, Sascha Weyers ${ }^{2}$ \\ From PSMR 2015: 4th Conference on PET/MR and SPECT/MR \\ La Biodola, Isola d'Elba, Italy. 17-21 May 2015
}

${ }^{1}$ Heidelberg University, Germany

We present single photon sensitive 2D camera chips containing $88 \times 88$ avalanche photo diodes which can be read out in full frame mode with up to 400.000 frames per second. The sensors have an imaging area of $\sim 5 \mathrm{~mm} \times 5 \mathrm{~mm}$ covered by square pixels of $\sim 56 \mu \mathrm{m} \times 56 \mu \mathrm{m}$ with a $\sim 55 \%$ fill factor in the latest chip generation. The chips contain a self triggering logic with selectable (column) multiplicities of up to $>=4$ hits within an adjustable coincidence time window. The photon accumulation time window is programmable as well. First prototypes have demonstrated low dark count rates of $<50 \mathrm{kHz} / \mathrm{mm} 2$ (SPAD area) at 10 degree C for $10 \%$ masked pixels. One chip version contains an automated readout of the photon cluster position. The readout of the detailed photon distribution for single events allows the characterization of light sharing, optical crosstalk etc., in crystals or crystal arrays as they are used in PET instrumentation. This knowledge could lead to improvements in spatial or temporal resolution.

Authors' details

${ }^{1}$ Heidelberg University, Germany. ${ }^{2}$ Fraunhofer Institute for Microelectronic Circuits and Systems, Germany.

Published: 18 May 2015

doi:10.1186/2197-7364-2-S1-A3

Cite this article as: Fischer et al: SPAD array chips with full frame readout for crystal characterization. EJNMM!

Physics 2015 2(Suppl 1):A3.

(c) 2015 Fischer et al; licensee Springer. This is an Open Access article distributed under the terms of the Creative Commons Attribution License (http://creativecommons.org/licenses/by/4.0), which permits unrestricted use, distribution, and reproduction in any medium, provided the original work is properly cited.

Submit your manuscript to a SpringerOpen ${ }^{\circ}$ journal and benefit from:

- Convenient online submission

- Rigorous peer review

- Immediate publication on acceptance

- Open access: articles freely available online

- High visibility within the field

- Retaining the copyright to your article

Submit your next manuscript at $\boldsymbol{~ s p r i n g e r o p e n . c o m ~}$ 